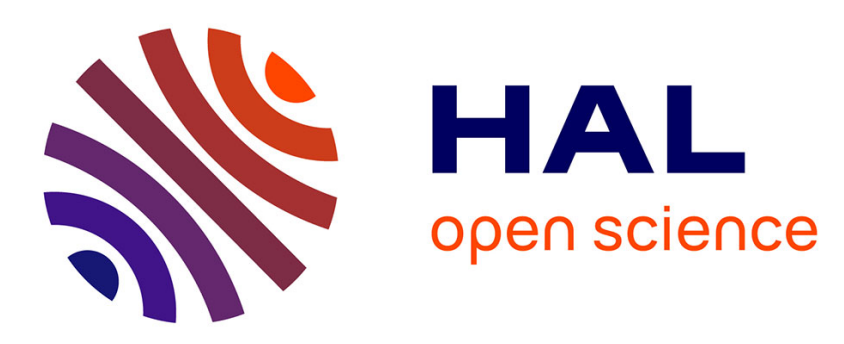

\title{
Evolution of resistance in Culex pipiens: Allele replacement and changing environment
}

Thomas Guillemaud, Thomas Lenormand, Denis D. Bourguet, Christine Chevillon, Nicole Pasteur, Michel Raymond

\section{- To cite this version:}

Thomas Guillemaud, Thomas Lenormand, Denis D. Bourguet, Christine Chevillon, Nicole Pasteur, et al.. Evolution of resistance in Culex pipiens: Allele replacement and changing environment. Evolution - International Journal of Organic Evolution, 1998, 52 (2), pp.443-453. 10.1111/j.15585646.1998.tb01644.x . hal-02696960

\section{HAL Id: hal-02696960 https: / hal.inrae.fr/hal-02696960}

Submitted on 1 Sep 2020

HAL is a multi-disciplinary open access archive for the deposit and dissemination of scientific research documents, whether they are published or not. The documents may come from teaching and research institutions in France or abroad, or from public or private research centers.
L'archive ouverte pluridisciplinaire HAL, est destinée au dépôt et à la diffusion de documents scientifiques de niveau recherche, publiés ou non, émanant des établissements d'enseignement et de recherche français ou étrangers, des laboratoires publics ou privés. 


\title{
EVOLUTION OF RESISTANCE IN CULEX PIPIENS: ALLELE REPLACEMENT AND CHANGING ENVIRONMENT
}

\author{
Thomas Guillemaud, Thomas lenormand, Denis Bourguet, Christine Chevillon, \\ Nicole Pasteur, and Michel Raymond ${ }^{1}$ \\ Institut des Sciences de l'Evolution, Laboratoire Génétique et Environnement (C.C. 065), UMR CNRS 5554, \\ Université de Montpellier II, F-34095 Montpellier, France \\ 'E-mail: Raymond@isem.univ-montp2.fr
}

\begin{abstract}
Fixation of adaptive mutations in populations is often constrained by pleiotropic fitness costs. The evolutionary pathways that compensate such fitness disadvantages are either the occurrence of modifier genes or replacement of the adaptive allele by less costly ones. In this context, 23 years of evolution of insecticide resistance genes in the mosquito Culex pipiens from southern France are analyzed. The aim of this study is to answer the following points. Is there a fitness cost associated with these resistance genes in natural populations? Does evolution proceed through allele replacement or through selection of modifiers? And finally, how do environmental changes affect the evolution of resistance genes? Samples from the same transect, crossing the boundary between an insecticide-treated and a nontreated area, are analyzed. Clinal analyses indicate a variable fitness cost among the resistance genes and show that allele replacement has been the primary mechanism of resistance evolution in this area. It is also shown that replacement was probably due to environmental changes corresponding to modification in pesticide-treatment intensity.
\end{abstract}

Key words.-Frequency cline, genetic succession, microevolution, natural populations, overproduced esterase, pleiotropy.

Received April 14, 1997. Accepted November 12, 1997.

One main subject in evolutionary biology is the understanding of adaptations in populations encountering new environments. Genetic variants selected for in the context of the novel circumstances have different properties depending on whether they are associated with negative pleiotropic effects (Caspari 1952; Wright 1968). Negative pleiotropic effects can subsequently be reduced by natural selection. This reduction, called "amelioration" of deleterious pleiotropic effects by Cohan et al. (1994), could be achieved by two means: allele replacement and compensatory allele accumulation. In the former case, an adaptive mutation with less deleterious pleiotropic effects is thought to replace the previous mutation and go to fixation in the population. The latter mode corresponds to the occurrence and selection of one or several new genes that modify or compensate the fitness cost. These two modes of evolution, which were previously proposed by Haldane (1932) and Fisher $(1928,1958)$, respectively, have been demonstrated in only a few biological cases (e.g., in Escherichia coli by Lenski et al. [1988a,b] and in Bacillus subtilis by Cohan et al. 1994). Indeed, when evolving populations become fixed for adaptive and ameliorative mutations, distinction between allele replacement and modifier gene occurrences is no longer possible, unless a genetic survey of the population is continuously conducted.

Pesticide resistance is a convenient model to study Darwinian processes in natural populations for two main reasons: selection is strong and evolution is fast. Molecular tools are now available to decipher, for each resistant species, the genetics of its new adaptation, giving the opportunity for new evolutionary insights. For example, mutations generating resistance genes are either classical point mutations or more complex molecular events such as gene amplification or gene regulation (reviewed in Taylor and Feyereisen 1996). Important constraints exist, in the sense that a very limited number of mutations are possible. This is indicated by the presence of the same mutation that has occurred independently in distinct species in response to the same pesticide (see Lee et al. [1988] and Guttieri et al. [1996] for the acetolactate synthase; Williamson et al. [1996] for the sodium channel; ffrench-Constant et al. [1996] for the $\mathrm{GABA}_{A}$ receptor of the chloride channel; and Rochaix and Erickson [1988], Kless et al. [1994], and Trebst [1996] for the D1 protein of photosystem II). Nonidentified constraints also exist for other mutations generating resistance. Esterase gene amplifications, conferring insecticide resistance in the mosquito Culex pipiens, have occurred a very limited number of times worldwide (Raymond et al. 1991; Guillemaud et al. 1996; Raymond et al. 1996). Another aspect is the pleiotropy effect of resistance genes, which is expressed sometimes in only some life history traits, and is still not well understood at the molecular level (Crow 1957).

There are few documented examples of deleterious effects and associated ameliorations. Observing such an evolution and its modality requires long-term field surveys such as those performed for Lucilia cuprina (McKenzie 1993; Clarke 1997). McKenzie and collaborators first described the adaptive gene (McKenzie et al. 1980) and its negative pleiotropic effects (McKenzie et al. 1982), then they detected the modifier gene (McKenzie and Purvis 1984; McKenzie 1993, 1994), and identified it at the molecular level (Davies et al. 1996; Clarke 1997).

Here, we report an analysis covering 23 years on the evolution of esterase resistance genes in the Montpellier (southern France) area where different pesticides (chlorpyrifos, temephos, fenitrothion, Bacillus sphaericus toxin) have been used to control $C$. pipiens. The occurrence of organophosphorous (OP) resistance and OP-resistance genes in this area has already been described (Pasteur and Sinègre 1975; Pasteur et al. 1981; Raymond et al. 1986; Chevillon et al. 1995). Basically, the first resistance gene (overproduced A1 ester- 


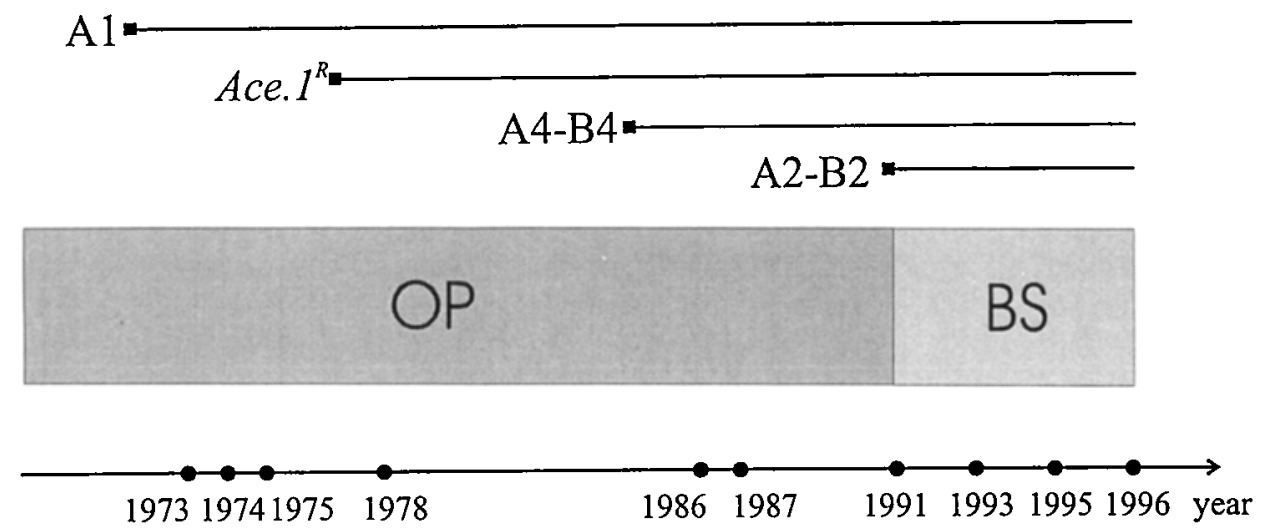

Fig. 1. Year of occurrence of the resistance genes in the region of Montpellier in relation with pesticides usage. Treatments with OP insecticides started in 1969 and were replaced by Bacillus sphaericus (BS) toxin from 1991 onward. Dots refer to the groups of samples along the transect used in this study (Fig. 2).

ase) occurred in 1972 , only four years after control began with chlorpyrifos (an OP insecticide). It was followed by the occurrence of a modified target (an insensitive acetylcholinesterase) in 1977, and by two pairs of overproduced esterase A and B allozymes: A4-B4 in 1984 and A2-B2 in 1991 (Fig. 1). Overproduction of $A 1$ esterase is due to a modification of esterase $A$ gene expression, while that of the associated esterases A4-B4 or A2-B2 is due to a tandem coamplification (increase in gene copy number) of the structural esterase $A$ and $B$ genes (Rooker et al. 1996). Although strictly speaking only $\mathrm{A} 4, \mathrm{~A} 2$, and $\mathrm{A} 1$ are alleles of the esterase $A$ locus and $\mathrm{B} 2$ and $\mathrm{B} 4$ are alleles at the esterase $B$ locus, A1, A4-B4, and A2-B2 behave as alleles of a single supergene due to the complete linkage disequilibrium between esterase $A$ and $B$ genes produced by the amplification. One particularly convenient feature of $C$. pipiens in the south of France is that pesticide treatments against this species have been managed to limit the treatment to the populations along the Mediterranean Coast. Thus, it is possible to identify in a linear transect orthogonal to the coastline an insecticide-treated area (close to the sea) and a nontreated area (further northwest; Fig. 2). On this transect, pesticide selection is variable in space, so that analysis of locally adaptive gene frequencies will give information on selection coefficients and migration, using the theory of clines (for review, see Felsenstein 1976).

In this study on $C$. pipiens resistance evolution, we focused on the following questions. Are the dynamics of long-term evolution of resistance genes characterized by allele accumulation or allele replacement? Is it possible to detect a selective cost associated with the esterase genes, and do these genes present the same cost? And finally, how did environmental changes such as limitation of insecticide treatments influence the dynamics of resistance genes?

\section{Materials and Methods \\ Mosquito Samples}

The total dataset contained 8724 mosquitoes in 112 epigeous (i.e., living in open-air habitat) samples from 52 localities along the northwest-southeast transect near Montpellier (southern France, Fig. 2) that crossed both treated and untreated areas. There were 12 sampling periods between July
1973 and May 1996. This dataset used all available samples from the same transect collected in 1973 (Entente Interdépartementale pour la Démoustication du Littoral Méditerranéen [EID], pers. comm.), 1974 (Pasteur and Sinègre 1975), 1975 (Pasteur 1977), 1978 (Pasteur et al. 1981), 1986 (Magnin 1986), 1987 (unpubl. data), 1991 (referred to as transect $\mathrm{K}$ in Chevillon et al. 1995) and 1993 (Chevillon et al. 1997). In addition, 36 mosquito samples were collected as larvae or adults between December 1995 and May 1996. Larvae were reared until adulthood and frozen for further analysis.

Among the 12 sampling periods, data from 1973, 1986, 1987,1995 , and 1996 are original data not published elsewhere. Moreover, the statistical analyses used in this study is original and has never been performed on the previously published data.

\section{Phenotypic and Genetic Analyses}

\section{Determination of Phenotypes from Insecticide Bioassay Data}

The only known OP-resistance mechanism prior to 1977 in the Montpellier area was overproduction of Al esterase (Pasteur and Sinègre 1975). Frequencies of this resistance phenotype in 1973 samples were determined using the results of insecticide bioassays of Pasteur and Sinègre (1975). The percentage of surviving mosquitoes exposed to concentrations of chlorpyrifos (referred as Dursban ${ }^{8}$ in Pasteur and Sinègre 1975) of $1.6 \times 10^{-3}$ and $3 \times 10^{-3} \mathrm{mg} / \mathrm{L}$ is an estimate of the frequency of $\mathrm{Al}$ phenotype.

\section{Electrophoretic Characterization}

Mosquitoes sampled in 1974, 1975, and 1978 were analyzed by Pasteur and collaborators (Pasteur and Sinègre 1975; Pasteur 1977; Pasteur et al. 1981) using the method described by de Stordeur (1976). This procedure allows clear visualization of the nonoverproduced esterases and thus allows determination of the esterase $A$ and $B$ loci genotypes. This method was not used after 1980 since overproduced esterases A4 and B4 mask part of the nonoverproduced esterases.

For mosquito samples collected after 1980 (including the present analysis of 36 samples), starch-gel electrophoreses 


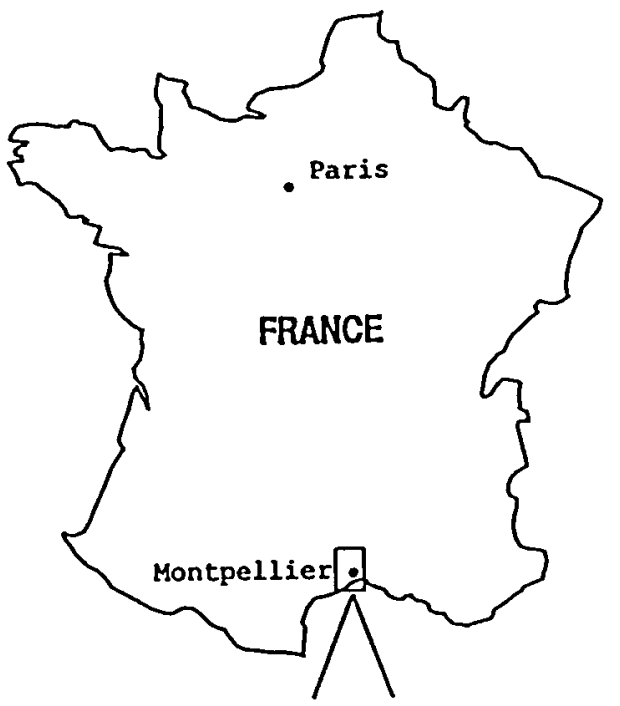

$s_{1} \cdots s_{2}$

$50^{\circ}$.

$47 . \quad .48$

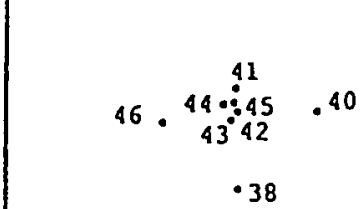

.39

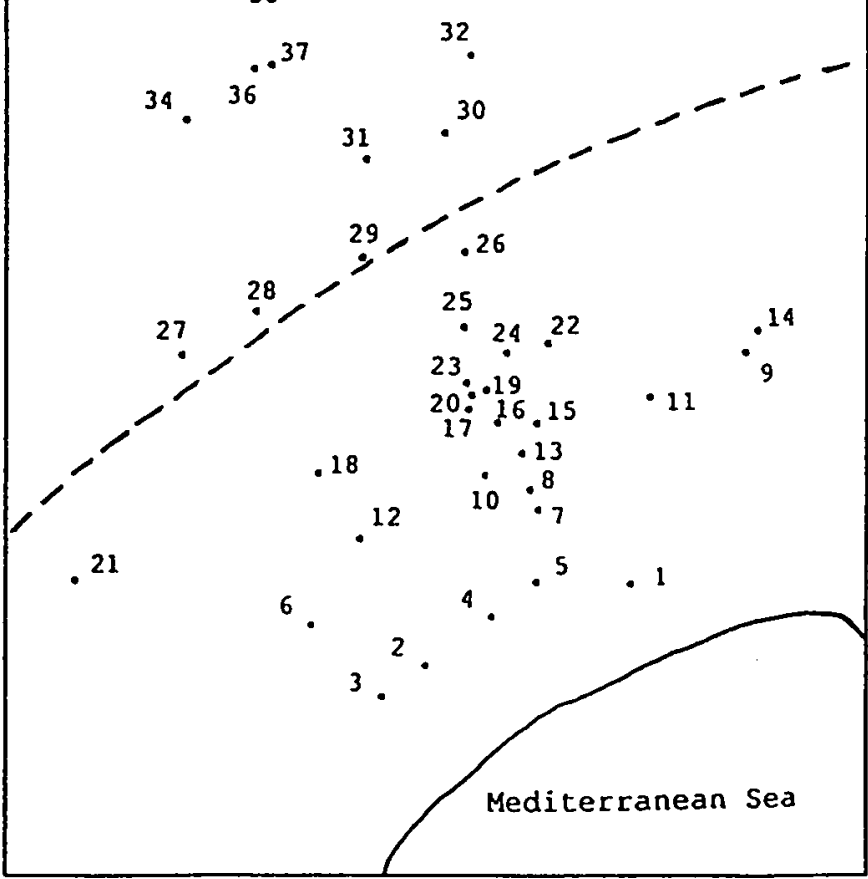

FIG. 2. Locations of samples along the northwest-southeast transect in the region of Montpellier (southern France). Numbers refer to sample identification (see Materials and Methods). The dotted line refers to the edge between treated and nontreated area in 1990. in TME-7.4 buffer on single mosquito homogenates were performed according to Pasteur et al. (1988) to detect the presence of highly active esterases. In each gel, mosquitoes from strains with known overproduced esterases were run as controls: strains BARRIOL with esterase A1 (Chevillon et al. 1995), SELAX with esterases A2-B2 (Wirth et al. 1990), and VIM with esterases A4-B4 (Poirié et al. 1992). This analysis did not allow the characterization of genotypes since with this electrophoretic technique heterozygotes and homozygotes for allele encoding overproduced esterases could not be discriminated. As a consequence, only resistance phenotype frequencies are available for samples collected after 1980 .

\section{RFLP Analyses}

RFLP analyses were carried out on 136 females sampled in Maurin in spring 1996. Single mosquito genomic DNA was obtained as described in Raymond and Marquine (1994) and digested with EcoRI. Gel migration, transfer, probe labeling, and hybridization were done as described by Raymond et al. (1989a). The probe for esterase $A$ and $B$ loci are described in Rooker et al. (1996). An equivalent procedure was also followed for some mosquitoes sampled in 1991 (Chevillon et al. 1995). These analyses only allow discrimination between A4-B 4 and A5-B5 haplotypes, because A4 and $B 4$ as well as A5 and B5 have the same electrophoretic mobility (Poirié et al. 1992).

Description of the samples and all phenotypic and genotypic data are available upon request.

\section{Data Comparison}

In this paper, three methods have been used to identify the resistant phenotype frequencies: insecticide bioassay for the 1973 dataset, and two different methods of esterase electrophoresis for all the other samples. These three methods can be used to compare data through time, as they give the same results (see the two next paragraphs). RFLP has not been used to estimate frequencies but rather to discriminate esterases A4-B4 and A5-B5 and to test Hardy-Weinberg equilibrium at the esterase locus.

Methods of Electrophoresis. - The only difference between the two methods of electrophoresis (de Stordeur 1976; Pasteur et al. 1988) was that nonoverproduced esterases could also be visualized (in addition to overproduced esterases) with the method used for mosquitoes sampled before 1980 and therefore allowed genotypic characterisation (Pasteur and Sinègre 1975; Pasteur 1977; Pasteur et al. 1981). Highly active esterases were revealed in the exact way in both protocols.

Insecticide Bioassay versus Electrophoresis.-In 1973, the only resistance mechanism present in southern France was esterase A1 (Pasteur and Sinègre 1975). Pasteur and Sinègre (1975) showed that a correlation between the mortality at the concentration of insecticide indicated and Al frequency detected by electrophoresis is 0.985 and highly significant. Therefore, insecticide bioassay is an appropriate method to estimate of $\mathrm{A} 1$ frequency in the samples, and the marginal residual variance of the correlation could only account for 
differences in frequency estimates of about 0.01 in each sample.

RFLP versus Electrophoresis.-RFLP has been used for one population of 1996 and some 1991 mosquitoes. For both dates, this method has only been used to verify that esterases A5-B5 were not present in the samples and to test HardyWeinberg equilibrium for the population of 1996 . However, comparison between RFLP and electrophoresis has been performed by Chevillon et al. (1995). They showed that A4-B4 esterase frequencies were slightly underestimated in electrophoresis because overproduction is sometimes insufficient for electrophoresis detection.

\section{Statistical Procedures}

\section{Hardy-Weinberg Equilibrium Test}

Whenever genotypes at esterase $A$ and $B$ loci were available (in 1974, 1975, 1978, and one 1996 sample), Hardy-Weinberg proportions were analyzed using the exact probability test of Guo and Thomson (1992). Four alleles were considered: the null (i.e., all alleles encoding a nonoverproduced esterase) and the resistance alleles encoding A1, A2-B2, and A4-B4 overproduced esterases. The statistical procedures were performed using the GENEPOP version 2 software (Raymond and Rousset 1995). Overall significance of several tests was computed using Fisher's method (Manly 1985).

\section{Variation of Resistant Gene Frequencies in Space and Time}

Tests were performed to analyze resistance genes distribution in relation to the geographic pattern of selection and to investigate the evolution of the different adaptive gene frequencies with time.

Given that electrophoretic and bioassay data gave only phenotypic identifications, three phenotypic classes were considered: $\left[R_{i}\right],\left[R_{i} / R_{j}\right]$ or $[O]$. Phenotype $\left[R_{i}\right]$ corresponds to homozygous $R_{i} R_{i}$ and heterozygous $R_{i} S$ genotypes, $\left[\mathrm{R}_{\mathrm{i}} / \mathrm{R}_{\mathrm{j}}\right.$ ] corresponds to heterozygous $R_{i} R_{j}$ genotypes, and [O] corresponds to $S S$ genotypes. $R_{i}$ is the allele encoding overproduced esterase(s) $i$ (i.e., A1, A4-B4, or A2-B2) and $S$ is any allele encoding a nonoverproduced esterase. In the following, the brackets refer to phenotype determination. In the result section, we show that genotypic frequencies are generally not at Hardy-Weinberg equilibrium so that allele frequency could not be inferred from phenotypic frequency.

In these analyses, we focused on one phenotype versus all others, for example, when the geographic variation of [A1] frequency was considered, we assumed a binomial error $B(n, p)$, where $p$ is the frequency of [A1] and $n$ the total number of individuals.

The geographic position of each sample was computed relative to the coast. It corresponds to the shortest geographic distance, $d$, to the sea after the projection of the sample location on an axis orthogonal to the coast (see Fig. 2). Time was described by two variables: $t$, a continuous quantitative variable describing the number of days between sampling date of the individual considered and the date of the first sample (2 July 1973), and $y$, a qualitative variable describing the year of sampling.

Effects of geographic distances $(d)$, sampling dates $(t)$, years $(y)$, and of interactions between time and distance variables on phenotypic frequencies were tested using a logistic model with the GLIM software (Baker and Nelder 1985).

We first tested (a) whether distance to the sea, $d$, affected phenotypic frequencies; and (b) whether such an effect varied with years, $y$. Step (a) was tested by analyzing the significance of the change in deviance when the variable $d$ is added to a model already incorporating the year factor $y$. This produces a common slope for each period of time (with different intercepts for each level of the temporal factor); the change in deviance was used to test whether this slope is significantly different from zero. Step (b) was tested by relaxing the slopes between time periods, thus allowing regressions to vary with $y$ (different slopes for different years). This new model was compared to the previous one to see whether the spatial pattern of phenotype frequencies depends on the sampling year considered.

Second, we tested the effect of $t, d$, and their interaction on the distribution of resistance phenotypes. This was performed by removing step by step the different variables from the complete model $t+d+t . d$.

\section{Analysis of Clines}

To analyze the clinal pattern of phenotypic frequencies, we used a model that corresponds better than the preceding logistic model to the case of semi-infinite clines. The presence of the sea at one extremity of the transect is a barrier to migration and, in such a case, logistic transformation does not depict the asymmetry of the clines. For example, at the bounded side of the cline there is a maximum frequency lower than one, and the slope of the curve at this point is theoretically null. This condition cannot be obtained with a logistic model. As there is no simple analytical solution for the semiinfinite cline model (Nagylaki 1975), we chose a simple form that fits quite well the data:

or

$$
p=h \times e^{-\left[d^{2}(w / h)^{2} e\right] / 2}
$$

$$
p=1-h \times e^{-\left[d^{2}(w / h)^{2} e \mid / 2\right.},
$$

where $h$ is the maximum frequency, $w$ corresponds to the maximum slope of the cline, and $d$ is the distance to the sea. These models are referred to here as exponential models. Equation (1) corresponds to frequencies increasing toward the sea, and equation (2) to the opposite trend.

For both logistic and exponential models, the significance of the effect of each variable, or interaction between variables, was tested using pseudolikelihood ratio tests using a modification of the metropolis algorithm adapted from $\mathbf{N}$. $H$. Barton (Szymura and Barton 1986). The calculation of the Akaike's (1973) information criterion (AIC) was also used. Likelihood ratio tests indicate the significance of the increase (or decrease) of a model deviance when removing (or adding) a variable or a group of variables from (to) this model. For example, two clines sampled at two different times could be compared by testing the null hypothesis of equality of the parameters $(h$ and $w$ ) between the clines using a likelihood ratio test (Szymura and Barton 1986).

To take into account overdispersion, we used $F$-tests instead of $\chi^{2}$-tests according to Crawley (1993). AIC was cal- 
culated as $d v+2 p m$, where $d v$ is the deviance of the model considered (i.e., $-2 \ln \left[L_{\max }\right]$ ) and $p m$ the number of independent parameters estimated in the model (number of parameters minus degree of freedom). The model with the smallest AIC was chosen.

\section{RESULTS}

\section{Identification of Esterase Resistance Genes}

Starch gel electrophoresis revealed several overproduced esterases in the region of Montpellier in 1995 and 1996, namely A1, the couple A2-B2, and a couple of esterases with the electrophoretic mobility of A4-B4 or A5-B5. To determine whether these last esterases were A4-B4 or A5-B5, an RFLP analysis was performed using EcoRI restriction enzyme. None of the 136 females sampled in Maurin during spring 1996 had $A 5$ and $B 5$ esterase genes, although 90 displayed the $A 4$ and $B 4$ esterase alleles RFLP pattern (details not shown). The same result was found by Chevillon et al. (1995) for samples of 1991. This suggests that esterases A5B5 were absent from the Montpellier area in 1991 and 1996.

\section{Hardy-Weinberg Equilibrium}

In the overall dataset, genotypes at esterase $A$ or $B$ loci were available for 26 populations sampled in 1974, 1975, 1978, and 1996. Hardy-Weinberg (H-W) equilibrium was rejected $(P<$ 0.05 ) for nine populations. In 1974 , seven populations were sampled and $\mathrm{H}-\mathrm{W}$ equilibrium was rejected for three populations displaying a heterozygote deficiency (Matelles: $\hat{F}_{i s}=$ $0.4, P=0.042$; Clapier: $\hat{F}_{i s}=0.9, P<10^{-5}$; Lattes $\hat{F}_{i s}=$ $0.6, P=6 \times 10^{-3}$ ). In $1975, \mathrm{H}-\mathrm{W}$ equilibrium was rejected in four of 13 populations (Montpellier: $\hat{F}_{i s}=0.22,-0.3$, and $0.6, P=0.038,10^{-4}$, and $<10^{-5}$; Lavérune: $\hat{F}_{i s}=-0.311$, $P=10^{-4}$ ). In 1978 , over five populations, the null hypothesis of $\mathrm{H}-\mathrm{W}$ equilibrium was rejected for two samples displaying a heterozygote deficiency (Claret: $\hat{F}_{i s}=0.9, P=7 \times 10^{-4}$; St Mathieu: $\hat{F}_{i s}=0.8, P=5 \times 10^{-3}$ ).

For each year, global tests indicated a departure from $\mathrm{H}$ W equilibrium (Fisher's method, $P<10^{-5}$ in 1974 and 1975 , and $P<10^{-3}$ in 1978). The only exception was the population of females from Maurin sampled in the spring 1996, where $\mathrm{H}-\mathrm{W}$ equilibrium was not rejected $(P=0.35)$. Given that, when genotypes are available $\mathrm{H}-\mathrm{W}$ equilibrium is often rejected, and because departure from $\mathrm{H}-\mathrm{W}$ equilibrium is not constant, allele frequencies cannot be computed. Therefore, the following analyses are based on the study of phenotypic frequencies: [A1], [A4-B4], [A2-B2], [O], [A1/A4-B4], [A1/ $\mathrm{A} 2-\mathrm{B} 2]$, and [A4-B4/A2-B2].

\section{Influence of Time on Phenotypic Frequencies}

Table 1 shows the significance of the effect of the sampling date, $t$, and sampling year, $y$, on the deviance of logistic models. They are all significant $\left(P<10^{-3}\right)$ for all phenotypes except [A1/A4-B4]. Basically the [A1] phenotype increased in frequency between 1973 and 1975 and decreased in the 1990s, while the [A4-B4] phenotype appeared in 1986 and continuously increased in frequency (see below for more detailed results). Overproduced esterases [A2-B2] appeared in 1991 and reached a mean frequency of $2.2 \%$ in 1996 . This

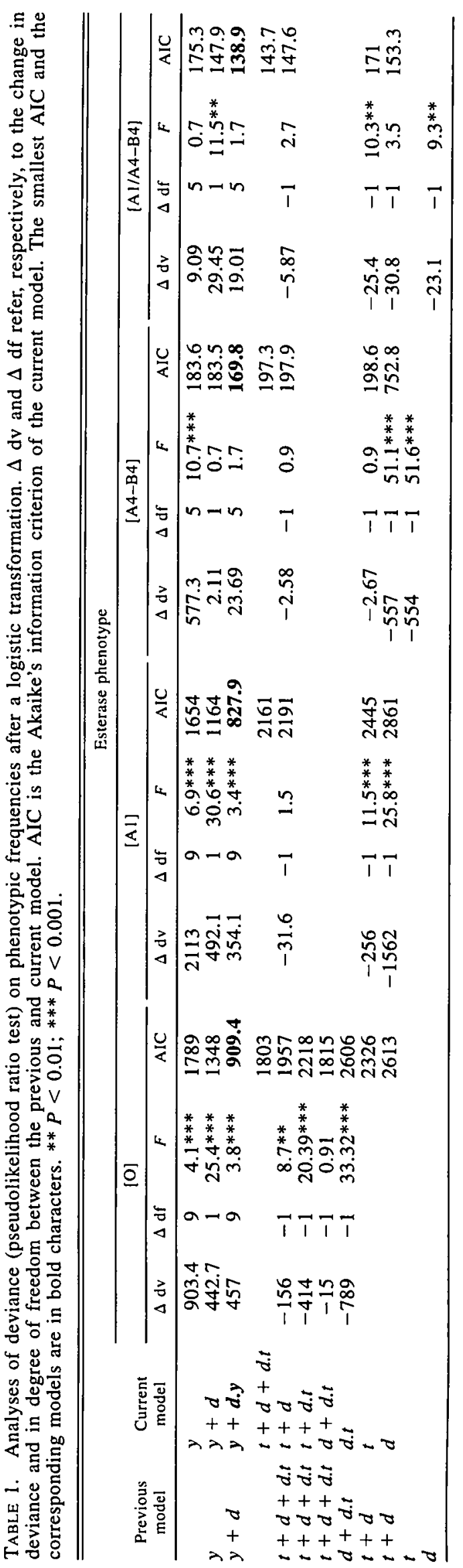


evolution was not analyzed in detail, since [A2-B2] frequency is extremely low.

\section{Spatial Variation of Phenotypic Frequencies}

Table 1 shows the effect of the distance from the sea, $d$, on the deviance of the models with the year, $y$, as factor, or the change in deviance when removing the distance parameter from the model fitted with $d+t$. In each case, changes of deviance were significant, that is, all phenotypes displayed a clinal spatial pattern, except [A4-B4]. Significance of interaction between time and distance are also presented. When samples are grouped by year $(y)$, the interaction term $(d . y)$ is significant for all phenotypes but those including A4-B4 esterases. This indicates that the slopes of the clines depend on the year considered. Interaction term $d . t$ is not significant except for the susceptible phenotype [O].

In addition, AIC values shows that models incorporating an interaction term between distance and year have lower AIC than models without this term. For each phenotype, the lowest AIC corresponds to model $y+d . y$. The combination of AIC computation and likelihood ratio tests indicates that variations in phenotype frequencies are best explained by the model describing a specific clinal spatial pattern of frequencies for each year $(y+d . y)$.

Because of the annual variability of the clines, we studied more precisely the different clines year by year.

\section{Fine Temporal Variation of Frequency Clines}

Figure 3 gives examples of clinal variations at different dates of sampling for [A1], [A4-B4], and [O], while Figure 4 shows the temporal variation of $h$ (the maximum frequency) and $w$ (the maximum slope) for [O], [A1], [A4-B4], and [A1/ A4-B4] phenotypes.

The change in [A1] frequency distribution was fast and substantial. It varied from a steep cline with maximum frequency close to 0.9 to a nonclinal pattern with mean frequency of about 0.1 . This evolution reveals at least three periods: (1) from 1973 to 1974, [A1] increased rapidly and significantly in frequency near the seashore, while the maximum slope, $w$, declined abruptly; (2) between 1974 and $1978, h$ remained quasiconstant and $w$ decreased continuously but was still large; $h$ was maximum in 1974 but in 1978 , the total number of A1-carrying individuals in the transect was maximum; this number is proportional to the integral of the frequency distribution that is $I=h^{2} \sqrt{\pi} /(w \sqrt{2 e})$ when clines are significant $(I=5.9$ in 1973, 20.4 in 1975, 24.3 in $1978,15.5$ in 1986, and 9.6 in 1983); and (3) after 1978, both $w$ and $h$ decreased continuously to low values. The temporal stability of pair of geographic distributions of phenotype is presented in Table 2 . After 1978, the transitions 1991-1993 and 1993-1995 are significant when tests are performed on both $h$ and $w$.

The [A4-B4] phenotype appeared in the samples in 1986 at low frequency (about 0.08 ) without a specific geographic distribution. Indeed, the fitted mean frequency along the transect was generally a better representation than a clinal distribution. The distribution of these esterases was clinal in spring 1991 and 1993. However, the clines were broad, with the associated slopes being very low. In 1993, [A4-B4] fre-
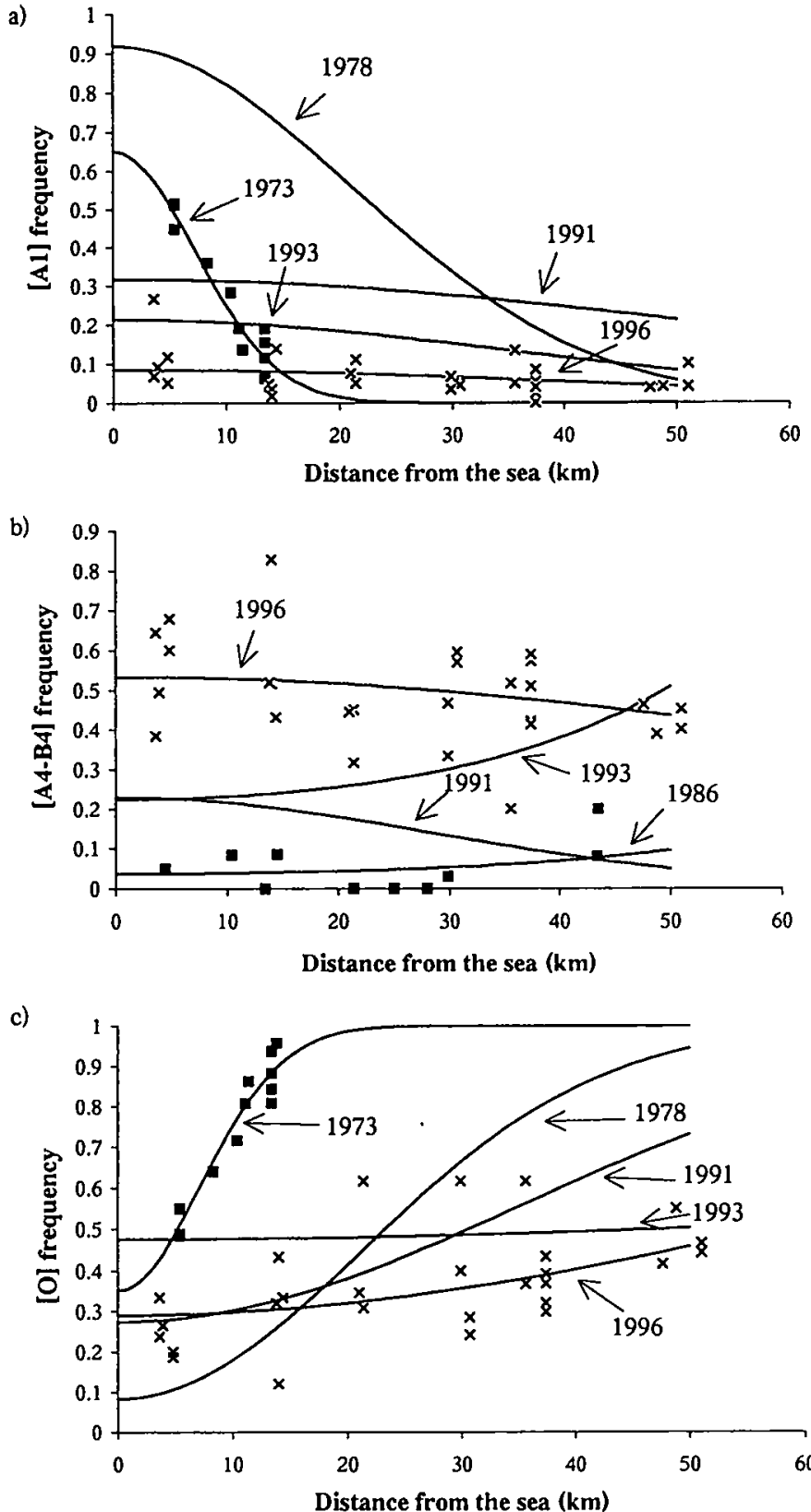

FIG. 3. Evolution of overproduced esterase phenotypes along the northwest-southeast transect of the Montpellier area. Examples are given for (a) [A1]; (b) [A4-B4]; and (c) [O] phenotypes as a function of the sampling year. For the sake of clarity, data points are given for the first (1973 for [A1] and [O] and 1986 for [A4-B4], designated by crosses) and last (1996, designated by squares) years of sampling only; fitted curves are given for additional years of sampling. The significance of the fits are given in Figure 4.

quencies were minimum near the seashore. The principal effect was temporal evolution since these esterases rapidly invaded the region, with their frequency reaching 0.3 in 1991 and 0.6 in 1996. The heterozygote genotype [A1/A4-B4] was at low frequency and presented clinal patterns of distribution except for the two last years, when esterase A1 was not frequent. In 1987 the cline of [A1/A4-B4] was steep; this corresponded to the period when $A 1$ and $A 4$ were both at a high frequency. 
a)

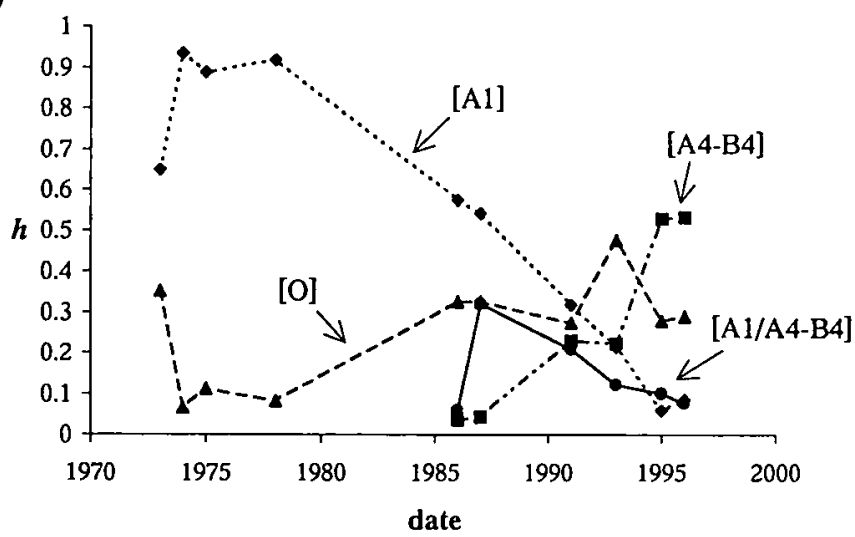

b)

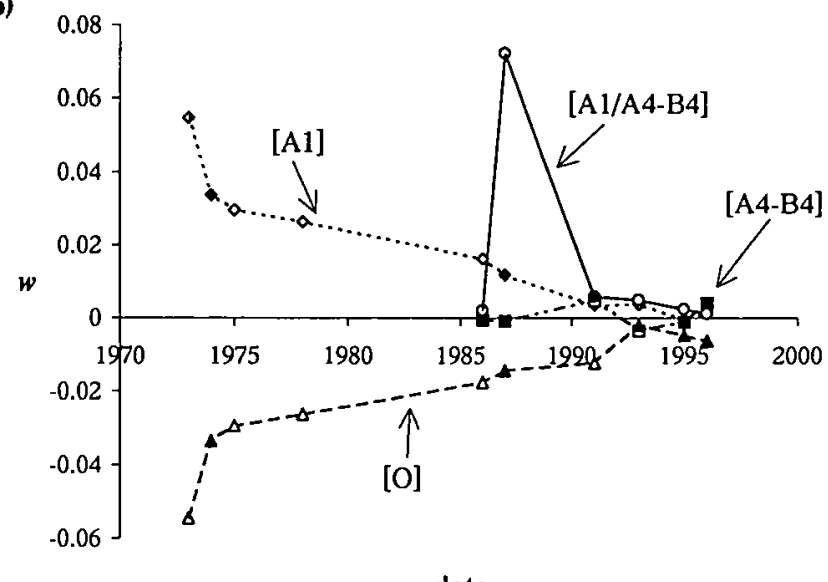

date

Fig. 4. Evolution of the frequency distribution of overproduced esterase phenotypes of each of the 12 sample groups since 1973 , given by the parameters of the exponential model of cline. (a) Evolution of the maximum frequency $h$; (b) evolution of the maximum slope $w$. Empty symbols refer to $w$-values significantly different $(P$ $<0.05$ ) from zero, that is, the distributions have a clinal pattern. Positive (respectively negative) values of $w$ refer to frequencies decreasing (increasing) from the sea.

\section{Discussion}

The survey of resistant alleles distributions over a period of 23 years reveals an extensive variation in space and in time in the south of France, where OP insecticides have been continuously used to control C. pipiens between 1969 and 1991. At first glance, their withdrawal after 1991 had no sharp effect on the evolution of esterase-resistance gene frequencies (Fig. 3). The maximum frequency of Al was lower after 1991, though the decrease started much earlier (in 1978). The maximum frequency of A4-B4 was higher after 1991, but because no data were available between 1987 and 1991 there may have been a regular increase since 1987. As A1 and A4-B4 are allelic, the decrease of A1 and the increase of A4-B4 correspond to an allele replacement. However the levels of resistance to the OP used (chlorpyrifos and temephos) provided by these two alleles are approximately equivalent (Raymond et al. 1986; Poirié et al. 1992), so that factors other than selection by insecticides must have operated. This is confirmed by the continuous increase of [A4-B4] frequency after 1991. More detailed considerations are required to better understand this situation.

\section{Different Costs for Different Mutations}

A case where an allele is selected for in a restricted area could lead to two different situations. First, if this allele is selectively neutral in the nontreated area (i.e., in the absence of insecticide), its distribution will depend on migration and no cline will be maintained. Second, if this allele is selected against in the nontreated area, theory predicts that the clinal distribution of the frequencies will depend on the size of the treated area, selection coefficients in both areas, and migration pattern. Chevillon et al. (1995) have demonstrated, using neutral gene polymorphism, that $C$. pipiens mosquitoes migrate extensively at the geographic scale considered in the present study, so that selection against an allele in the nontreated area is a necessary condition for the initiation and the maintenance of a cline (Nagylaki 1975). Therefore, the clinal distribution of resistance genes in southern France can be best explained if they have a fitness disadvantage (a fitness cost). The slope and the maximum frequency of a cline should provide qualitative information about the relationship be-

TABLE 2. Tests of the stability of sample frequency distributions by pairwise comparisons. For each pair, stability was tested by computing the change in deviance $(\Delta \mathrm{dv})$ and the corresponding $F$-ratio between the independent fit of the two frequency distributions (fitting two slopes and two maximum frequencies) and the global fit where the slope and the maximum frequency are the same for the two time periods (see text for details). The model used is the exponential model, $n$ is the number of populations in each couple of transects. When data are not overdispersed, significance of $\chi^{2}$-test is given instead of $F$-test. $* P<0.05 ; * * P<0.01 ; * * * P<0.001$.

\begin{tabular}{|c|c|c|c|c|c|c|c|c|}
\hline \multirow[b]{3}{*}{ Transects } & \multicolumn{8}{|c|}{ Esterase phenotype } \\
\hline & \multicolumn{2}{|c|}{ [O] } & \multicolumn{2}{|c|}{$[A \mid]$} & \multicolumn{2}{|c|}{$[\mathrm{A} 4-\mathrm{B} 4]$} & \multicolumn{2}{|c|}{ [A1/A4-B4] } \\
\hline & $\Delta d v$ & $F(2 ; n-4)$ & $\Delta \mathrm{dv}$ & $F(2 ; n-4)$ & $\Delta \mathrm{dv}$ & $F(2 ; n-4)$ & $\Delta d v$ & $F(2 ; n-4)$ \\
\hline $1973-1974$ & 371.52 & $13.40 * * *$ & 371.52 & $13.40 * * *$ & & & & \\
\hline $1974-1975$ & 1.20 & 0.02 & 1.20 & 0.02 & & & & \\
\hline $1975-1978$ & 11.90 & 0.24 & 11.90 & 0.24 & & & & \\
\hline $1978-1986$ & 21.16 & 0.69 & 49.34 & 1.82 & & & & \\
\hline $1986-1987$ & 2.07 & 0.13 & 2.07 & 0.22 & 0.71 & 0.18 & 1.57 & 0.65 \\
\hline $1987-1991$ & 3.21 & 0.40 & 4.39 & 1.20 & 6.99 & $x^{2}(2)^{*}$ & 9.86 & 1.64 \\
\hline $1991-1993$ & 8.35 & $3.82 *$ & 11.59 & $4.15^{*}$ & 43.54 & $24.12 * * *$ & 9.55 & 1.90 \\
\hline $1993-1995$ & 35.84 & $11.94 * * *$ & 34.81 & $4.56 *$ & 68.78 & $30.14 * * *$ & 6.53 & 2.22 \\
\hline $1995-1996$ & 6.10 & 1.74 & 3.03 & 0.96 & 7.05 & 2.11 & 3.95 & $x^{2}(2)$ \\
\hline
\end{tabular}


tween selection and cost for a given migration rate and a given size of treated area.

The clines of [A1] were steep until 1987. This suggests that, at least until 1987, mosquitoes displaying overproduced esterase A1 were submitted to a strong fitness cost. After 1987, Al esterase decreased in frequency and its clinal distribution disappeared.

[A4-B4] always had a broad distribution. When it was first detected in southern France (1984), its frequency was low and its distribution was uniform across treated and nontreated areas (Magnin 1986). In spring 1993, when [A1] and [A4B4] phenotypes had a similar frequency close to the sea ( $21 \%$ and $22 \%$, respectively), [A1] had a clinal distribution, but [A4-B4] did not. Given that gene flow, size of treated area, and pesticide treatments were clearly the same for both phenotypes, we must consider that the ratio of fitness cost over positive selection affecting [A4-B4] individuals is lower than that affecting [A1]. Thus, overproduced esterases A1 and A4B4 have different fitness costs to resistant mosquitoes.

\section{Why Do Resistance Alleles Have Different Fitness Costs?}

Previous studies have indicated that the A1 esterase was selected against in the laboratory (Raymond et al. 1985a,b) and in the field (Chevillon 1994; Chevillon et al. 1997) in the absence of insecticides. Here we showed that A1 esterase confers an important decrease in fitness in the nontreated area, but that esterases A4-B4 do not. Two characteristics of A1 and A4-B4 resistance genes can account for this. First, the amount of overproduced enzyme could be lower for A4-B4 than for Al, and second the different molecular mechanisms by which overproduction is achieved may be involved.

There is no clear evidence for the first point, since immunoblot analyses have revealed an overproduction of $50 \mathrm{X}$ and $70 \mathrm{X}$ for B4 and A1 esterases, respectively, in homozygous laboratory strains (Mouchès et al. 1987; Poirié et al. 1992). Thus, the energy invested in the overall esterase production is equivalent in the two cases, or even slightly lower for A1 than for A4-B4. The molecular origin of esterase overproduction is gene amplification for A4-B4 esterase (Poirié et al. 1992; Rooker et al. 1996) and a cis-acting regulatory mechanism for A1 (Rooker et al. 1996).

In their review on the relationships between molecular mechanism of resistance and fitness components, Taylor and Feyereisen (1996) showed that moderate gene amplification should be associated with low fitness cost and that up regulatory mechanism should provide high fitness cost. They also suggested that cis-acting regulatory factors could be moderately abundant in early resistance evolution and then should be replaced by less costly resistance genes. Overproduced esterase Al is due to such a mechanism (Rooker et al. 1996). The case of $\mathrm{A} 1$ and A4-B4 in C. pipiens seems to be an example for this theoretical scenario. The amplification level (the gene copy number) in a strain homozygous for overproduced esterase A4-B4 was measured twice on the same strain maintained in absence of selection. It was $25-$ fold in 1991 (Poirié et al. 1992) and five- to eightfold in 1996 (TG, unpubl. data). This last observation supports the idea that amplification level is able to rapidly evolve, probably by unequal crossing over, as predicted by theory focused on gene amplification in cultured cells (Axelrod et al. 1994). However, how fast the regulation mechanism responsible for A1 overproduction may evolve is not known. Also, whether this difference in molecular mechanism involved in esterase overproduction explains the difference in fitness cost remains to be investigated.

\section{Environmental Changes}

The evolution of $\mathrm{A} 1$ can be divided into three phases: (1) the increase of its frequency in the early 1970s; (2) a short, stable phase during which the cline was steep and the maximum frequency was large (up to $90 \%$ ); and (3) the decrease of the height and the slope of the cline between 1978 and 1996.

During the 23 years of this survey, different events occurred that relate to OP resistance conferred by the A1 esterase. Treatments changed in space and time, and new resistance genes have occurred.

Two new resistance genes occurred successively in the Montpellier area. First, a new resistance mechanism, a modified target of OP insecticides (Raymond et al. 1986), appeared in southern France in 1977. The modified target is an insensitive acetylcholinesterase encoded by a resistant allele $\left(\right.$ Ace.1 ${ }^{R}$ ) at the Ace.1 locus (Bourguet et al. 1996). This mechanism provides a generally higher resistance to insecticides (temephos, chlorpyrifos) used in natural populations than do overproduced esterases (Raymond et al. 1986; Poirié et al. 1992). Second, new overproduced esterases A4-B4 appeared in natural populations.

The size of the treated area was extended year by year. Considering this expansion to the north, theory (Nagylaki 1975) predicts that $A 1$ frequency should have increased close to the sea and that the center of the cline should have shifted further north. The first effect is apparent between 1973 and 1978, but not after 1978 and might have been opposed by the other environmental changes after 1978 while the latter phenomenon is observed.

In addition, insecticide treatments against mosquitoes changed quantitatively and qualitatively twice. First, due to the high resistance provided by $A c e . l^{R}$ (which occurred in 1977), chlorpyrifos doses were increased in 1978 onward, and other OP insecticides (temephos and fenitrothion) were introduced in 1981. Second, a Bacillus sphaericus toxin largely replaced chemical pesticides in 1991. Use of OP insecticides was not completely stopped, but was less frequent and limited (Anonymous 1991).

Changes of both abiotic (insecticide treatments) and biotic (new resistant alleles) environments modified the selective processes affecting Al. Indeed, Ace. $1^{R}$ increased rapidly in frequency, reaching maximum frequencies of $30 \%$ in 1986 (Magnin 1986), 70\% in 1987 (unpubl. data), and 80\% in 1991 (Chevillon et al. 1995). It has been shown theoretically and empirically that when an insensitive target and a detoxification resistance mechanism are both present, the overall resistance is additive (Raymond et al. 1989b). As a consequence, due to presence of an insensitive target providing by itself a high resistance, the contribution to overall resistance of $\mathrm{Al}$ is much lower than when $\mathrm{Al}$ is alone. The increase in frequency of $A c e . I^{R}$ in natural populations thus decreases the 
ratio of positive selection over cost for $\mathrm{A} 1$, leading to smaller values of both height and slope of the Al clines.

In 1991, when the abiotic environment changed with the partial replacement of OP insecticides by $B$. sphaericus toxins, the selection pressure favoring overproduced esterases declined since they provide no protection against these toxins (Nielsen-Leroux et al. 1997). By analyzing the shape of the frequency distribution (this study; Chevillon et al. 1995) and by measuring some fitness components in the laboratory (Raymond et al. 1985a) and in the field (Chevillon 1994; Chevillon et al. 1997) our data indicate that Al overproduced esterase allele was selected against. We have shown that the cost must be smaller for A4-B4 overproduced esterases than for Al. Although very little is known about dominance and epistasy of the cost, this difference is a suitable explanation for the invasion of A4-B4 resistant allele. Indeed, after 1991, OP-insecticide treatments became cryptic and thus the positive selective advantage of both $\mathrm{A} 1$ and A4-B 4 alleles became low and comparable, one obvious remaining difference being the cost of the resistance mechanism involved.

\section{The Local Paradox of A2-B2 Esterase}

Although A2-B2 (a third resistant allele of the esterase Aesterase $B$ supergene) is distributed worldwide, its frequency in the Montpellier area has been very low since its first detection in 1990. The maximum mean frequency was reported in 1995 at 0.03 . It is noteworthy that A2-B2 has been detected at high frequency $(0.18)$ in 1987 less than $100 \mathrm{~km}$ east of Montpellier (Rivet et al. 1993) and has not yet invaded the Montpellier area. There is little direct evidence that these esterases are associated with a fitness cost in the laboratory (Bonning and Hemingway 1991). However, indirect studies on resistance gene frequency in natural populations have shown that A2-B2 esterases have disappeared in Lucca, Italy, after the cessation of OP treatments in 1989 (Severini et al. 1993). Therefore, given that migration at this geographical scale is not limiting, a putative fitness cost of A2-B2 could have prevented its invasion in a region and during a period where OP treatments were not intense enough.

\section{Is A4-B4 a Local Optimal Strategy?}

Four different adaptive molecular mechanisms (A1, Ace. $1^{R}$, A4-B4 and A2-B2) have successively appeared since 1973 along the French Mediterranean Coast in response to intense insecticide treatments; three of them (A1, Ace. $1^{R}$, and A4B4) have invaded the Montpellier area. Today, two (Ace. $I^{R}$ and A4-B4) have a frequency higher than 0.5 in this area. Although worldwide migration of some other overproduced esterase like A2-B2 or B1 has been documented, overproduced esterases A1 and A4-B4 are only present in Mediterranean countries. In the studied area, overproduced esterase $\mathrm{Al}$ is now at very low frequency because of the change of OP treatments leading to the subsequent reduction of the positive selection for $\mathrm{A} 1$ and of the occurrence of A4-B4 leading to allelic competition and replacement. The relative dynamics of these alleles is best explained by their different fitnesses in an evolving environment. The preponderance of A4-B4 seems to be directly related to the local change of insecticide treatments in the early 1990s and the type of mu- tations responsible for the overproduction. This scenario is likely to have occurred in other places where OP treatments decreased. For example, it seems that in Lucca, Italy, where OP treatments stopped in 1989, and in Montpellier areas, situations are equivalent. The picture of esterases frequency in Lucca given by Severini et al. (1993) in 1993 compared to that of 1986 (Villani and Hemingway 1987) shows that Al esterase frequency decreased (from 0.39 to 0.21 ), while that of A4-B4 increased (from 0.00 to 0.57 ). Moreover, given the propensity of $C$. pipiens mosquitoes for migration, we might predict that A4-B4 should be able to invade other places in the world where a comparable decrease of OP treatments could favor a resistance gene providing only a low resistance level but with a very low (if any) fitness cost.

Other changes in the resistance genes are probable in southern France. First, it has been recently shown that overproduced esterases A5-B5 are now occurring in western Europe, while they were only recorded in Cyprus in 1987 (Severini et al., in press). This invasion, described in Lignano (northeastern Italy) where OP treatments are intense, probably results from allelic competition with A4-B4 esterase, as OP resistance conferred by A5-B5 is far greater than that of A4B4 (Poirié et al. 1992), which were the most frequent esterases in this region in 1993 (Severini et al. 1993). Moreover, abiotic environmental changes are likely to occur in southern France since a high resistance to $B$. sphaericus toxins has already been locally described (Sinègre et al. 1994; NielsenLeroux et al., in press).

\section{Allele Replacement versus Amelioration by Accumulation}

It is noteworthy that evolution toward genes modifying the fitness cost (modifier genes) of resistance esterase genes have not been observed in $C$. pipiens. Although the literature is abundant on this subject, only very few examples have been described. This phenomenon is particularly well studied in the Australian sheep blowfly Lucilia cuprina (Clarke 1997), in which diazinon resistance due to an altered carboxylesterase encoded by Rop-1 locus was associated with a fitness cost (McKenzie et al. 1982). The authors have demonstrated that a fitness cost modifier was responsible for the absence of fitness disadvantage of resistant individuals (Clarke and McKenzie 1987; McKenzie and Game 1987) and have recently characterized a candidate gene for this modifier (Davies et al. 1996). This amelioration of pleiotropic effects by acquisition of a modifier (i.e., acquisition of a new allele at another locus) is in contrast with the $C$. pipiens example. We suggest that, in this species, at least for OP resistance due to esterase overproduction, the amelioration of pleiotropic cost has been achieved by allele replacement (i.e., substitution of the costly allele by a less costly one at the locus involved in resistance).

\section{ACKNOWLEDGMENTS}

We are grateful to C. Bernard, M. Marquine, and G. Pistre for technical assistance and to J. Werren, A. Jubal, P. Jarne, and F. Rousset for helpful comments and discussions. We would like to thank the people who have participated with the sampling; P. Dias, E. Dupont, D. Heyse, S. Huck, B. Gaven, M. Magnin, E. Marboutin, V. Maringue, M. Michaud, A. 
Pasteur, V. Perrot, E. Poulin, F. Rousset, and M. Weill. The Entente Interdépartementale pour la Démoustication du Littoral Mediterranéen (EID) is particularly acknowledged for providing details on treatments and resistance data of 1973 samples. This work was financed in part by a Programme Environnement, Vie and Société of the CNRS (GDR 1105), the region Languedoc-Roussillon (963223), ACC (SV39503037), and a CEE grant (ERBCHRXCT930172). TG benefited from a MESR fellowship (94137). This is contribution ISEM 98.035 of the Institut des Sciences de l'Evolution (UMR CNRS 5554).

\section{Literature Cited}

AKAIKE, H. 1973. Information theory and an extension of the maximum likelihood principle. Pp. 267-281 in B. N. Petran and F. Csaki, eds. International symposium on information theory. Akademiai Kiadi, Budapest.

ANonymous. 1991. Rapport d'Acitivité 1991. Entente Interdépartementale pour la Démoustication du Littoral Méditerranéen. Montpellier, France.

Axelrod, D. E., K. A. Baggerly, AND M. Kimmel. 1994. Gene amplification by unequal sister chromatid exchange: probabilistic modeling and analysis of drug resistance data. J. Theor. Biol. 168:151-159.

Baker, R. J., AND J. A. Nelder. 1985. The glim system. Rel. 3.77. Algorithm Groups, Oxford.

BonNING, B. C., AND J. HEMINGWAY, 1991. Identification of reduced fitness associated with an insecticide resistance gene in Culex pipiens by microtitre plate tests. Med. Vet. Entomol. 5: 377-379.

Bourguet, D., M. Raymond, D. Fournier, C. A. Malcolm, J.-P. Toutant, AND M. ARPagaus. 1996. Existence of two acetylcholinesterases in the mosquito Culex pipiens (Diptera: Culicidae). J. Neurochem. 67:2115-2123.

Caspari, E. 1952. Pleiotropic gene action. Evolution 6:1-18.

Chevillon, C. 1994. Evolution de mécanismes adaptatifs: flux géniques, sélection et contre-sélection. Ph.D. diss., University of Montpellier II, Montpellier, France.

Chevillon, C., N. Pasteur, M. Marquine, D. Heyse, and M. RAYMOND. 1995. Population structure and dynamics of selected genes in the mosquito Culex pipiens. Evolution 49:997-1007.

Chevillon, C., D. Bourguet, F. Rousset, N. Pasteur, and M. RAYMOND. 1997. Pleiotropy of adaptive changes in populations: comparisons among insecticide resistance genes in Culex pipiens. Genet. Res. 68:195-203.

Clarke, G. M. 1997. The genetic and molecular basis of developmental stability: the Lucillia story. Trends Ecol. Evol. 12:8991.

Clarke, G. M., and J. A. McKenzie. 1987. Developmental stability of insecticide resistant phenotypes in blowfly: a result of canalizing selection. Nature 325:345-346.

Cohan, F. M., E. C. King, AND P. ZaWADZKI. 1994. Amelioration of the deleterious pleiotropic effects of an adaptive mutation in Bacillus subtilis. Evolution 48:81-95.

Crawley, M. J. 1993. GLIM for ecologists. Blackwell Scientific, Oxford.

Crow, J. F. 1957. Genetics of insect resistance to chemicals. Annu. Rev. Entomol. 2:227-246.

Davies, A. G., A. Y. Game, Z. Chen, T. J. Williams, S. Goodall J. L. Yen, J. A. McKenzIE, AND P. BATterham. 1996. Scalloped wings is the Lucilia cuprima Notch homologue and a candidate for the Modifier of fitness and asymmetry of diazinon resistance. Genetics 143:1321-1337.

DE STORDEUR, E. 1976. Esterases in the mosquito Culex pipiens pipiens $\mathrm{L}$.: formal genetics and polymorphism of adult esterases. Biochem. Genet. 14:481-493.

FELSENSTEIN, J. 1976. The theoretical population genetics of variable selection and migration. Annu. Rev. Genet. 10:253-280.

FFRENCH-CONSTANT, R. H., N. M. ANTHONY, D. ANDREEV, AND K. ARONSTEIN. 1996. Single versus multiple origins of insecticide resistance: inferences from the cyclodiene resistance gene $R d l$. Pp. 106-116 in T. M. Brown, ed. Molecular genetics and evolution of pesticide resistance. American Chemical Society, Washington, DC.

FISHER, R. A. 1928. The possible modification of the responses of wild type to reccurrent mutations. Am. Nat. 62:115-126.

. 1958. The genetical theory of natural selection. Dover, New York.

Guillemaud, T., S. Rooker, N. Pasteur, and M. Raymond. 1996. Testing the unique amplification event and the worldwide migration hypothesis of insecticide resistance genes with sequence data. Heredity 77:535-543.

Guo, S. W., AND E. A. ThOMPSon. 1992. Performing the exact test of Hardy-Weinberg proportions for multiple alleles. Biometrics 48:361-372.

Guttieri, M. J., C. V. Eberlein, C. A. Mallory-Smith, and D. C. THILL. 1996. Molecular genetics of target-site resistance to acetolactate synthase inhibiting herbicides. Pp. 10-16 in T. M. Brown, ed. Molecular genetics and evolution of pesticide resistance. American Chemical Society, Washington, DC.

Haldane, J. B. S. 1932. The causes of evolution. Harper, New York.

Kless, H., M. ORen-ShamiR, S. Malkin, L. Mclntosh, and M. Edelman. 1994. The D-E region of the D1 protein is involved in multiple quinone and herbicide interactions in photosystem II. Biochemistry 33:10501-10507.

Lee, K. Y., J. Townsend, J. Tepperman, M. Black, C. F. Chui, B. Mazur, P. Dunsmuir, AND J. BEDBROOK. 1988. The molecular basis of sulfonylurea herbicide resistance in tobacco. EMBO J. 7:1241-1248.

LENSKI, R. E. 1988a. Experimental studies of pleiotropy and epistasis in Escherichia coli. I. Variation in competitive fitness among mutatn resistant to virus T4. Evolution 42:425-432.

. 1988b. Experimental studies of pleiotropy and epistasis in Escherichia coli. II. Compensation for maladaptive effects associated with resistance to virus T4. Evolution 42:433-440.

MAGNIN, M. 1986. Résistance aux insecticides organophosphorés: détection, caractérisation, génétique et dynamique dans les populations naturelles. Ph.D. diss. Univ. of Paris VI, Paris.

MANLY, B. F. J. 1985. The statistics of natural selection. Chapman and Hall, London.

McKenziE, J. A. 1993. Measuring fitness and intergenic interactions: the evolution of resistance to diazinon in Lucilia cuprina. Genetica 90:227-237.

. 1994. Selection at the diazinon resistance locus in overwintering populations of Lucilia cuprina (the Australian sheep blowfly). Heredity 73:57-64.

McKenzIE, J. A., AND A. Y. GAME. 1987. Diazinon resistance in Lucilia cuprina; mapping of a fitness modifier. Heredity 59:371381.

McKenzie, J. A., ANd A. Purvis. 1984. Chromosomal localisation of fitness modifiers of diazinon resistance genotypes of Lucilia cuprina. Heredity 53:625-634.

MCKenzie, J. A., J. M. DEARn, AND M. J. Whitten. 1980. Genetics basis of resistance to diazinon in victorian populations of the australian sheep blowfly, Lucilia cuprina. Austr. J. Biol. Sci. 33: $85-95$.

McKenzie, J. A., M. J. Whitten, and M. A. Adena. 1982. The effect of genetic background on the fitness of diazinon resistance genotypes of the australian sheep blowfly, Lucilia cuprina. Heredity $49: 1-9$.

Mouchès, C., M. Magnin, J.-B. Bergé, M. DE Silvestri, V. BeysSAT, N. PAsteur, AND G. P. GeORghiou. 1987. Overproduction of detoxifying esterases in organophosphate-resistant Culex mosquitoes and their presence in other insects. Proc. Nat. Acad. Sci. USA 84:2113-2116.

NAGYLAKI, T. 1975. Conditions for the existence of clines. Genetics 80:595-615.

Nielsen-Leroux, C., F. Pasquier, J.-F. Charles, G. Sinègre, B. Gaven, AND N. Pasteur. 1997. Resistance to Bacillus sphaericus involves different mechanisms in Culex pipiens (Diptera: Culicidae) larvae. J. Med. Entomol. 34:321-327.

Pasteur, N. 1977. Recherche de génétique chez Culex pipiens 
pipiens L. Polymorphisme enzymatique, autogénèse et résistance aux insecticides organophosphorés. Ph.D. diss., University of Montpellier II, Montpellier, France.

Pasteur, N., AND G. SinĖgRE. 1975. Esterase polymorphism and sensitivity to dursban organophosphorus insecticide in Culex pipiens pipiens populations. Biochem. Genet. 13:789-803.

Pasteur, N., G. Sinègre, and A. Gabinaud. 1981. Est-2 and Est3 polymorphism in Culex pipiens $\mathrm{L}$. from southern France in relation to organophosphate resistance. Biochem. Genet. 19: 499-508.

Pasteur, N., G. Pasteur, J. Catalan, F. Bonhomme, and J. BritTON-DAvidian. 1988. Practical isozyme genetics. Wiley/Horwood, Chichester.

Poirié, M., M. Raymond, AND N. Pasteur. 1992. Identification of two distinct amplifications of the esterase B locus in Culex pipiens (L.) mosquitoes from mediterranean countries. Biochem. Genet. 30:13-26.

Raymond, M., AND M. Marquine. 1994. Evolution of insecticide resistance in Culex pipiens populations: the Corsican paradox. J. Evol. Biol. 7:315-337.

RAyMOND, M., AND F. Rousset. 1995. GENEPOP. Vers. 1.2. A population genetics software for exact tests and ecumenicism. J Hered. 86:248-249.

Raymond, M., B. Gaven, N. Pasteur, and G. Sinègre. 1985a. Etude de la résistance au chlorpyrifos à partir de quelques souch es du moustique Culex pipiens L. du sud de la France. Genet. Sel. Evol. 17:73-88.

Raymond, M., N. Pasteur, D. Fournier, A. Cuany, J. B. Bergé, AND M. MAGnin. 1985b. Le gène d'une acétylcholinestérase insensible au propoxur détermine la résistance de Culex pipiens L. à cet insecticide. C. R. Acad. Sci. Paris, Serie III 300:509512.

Raymond, M., D. Fournier, J.-M. Bride, A. Cuany, J. Bergé, M. MAGNin, AND N. PASTEUR. 1986. Identification of resistance mechanisms in Culex pipiens (Diptera: Culicidae) from southern France: insensitive acetylcholinesterase and detoxifying oxidases. J. Econom. Entomol. 79:1452-1458.

Raymond, M., V. Beyssat-Arnaouty, N. Sivasubramanian, C. Mouches, G. P. Georghiou, and N. Pasteur. 1989a. Amplification of various esterase Bs responsible for organophosphate resistance in Culex mosquitoes. Biochem. Genet. 27:417-423.

RAYMOND, M., D. HeCKel, AND J. G. ScOTT. 1989b. Interaction between pesticide genes: model and experiment. Genetics 123: $543-551$

Raymond, M., A. Callaghan, P. Fort, and N. Pasteur. 1991. Worldwide migration of amplified insecticide resistance genes in mosquitoes. Nature 350:151-153.

Raymond, M., C. L. Qiao, AND A. Callaghan. 1996. Esterase polymorphism in insecticide susceptible populations of the mosquito Culex pipiens. Genet. Res. 67:19-26.
Rivet, Y., M. Marouine, and M. Raymond. 1993. French mosquito populations invaded by A2-B2 esterases causing insecticide resistance. Biol. J. Lin. Soc. 49:249-255.

RoChAIX, J.-D., AND J. ERICKSON. 1988. Function and assembly of photosystem. II. Genetics and molecular analysis. Trends Biochem. Sci. 13:56-59.

Rooker, S., T. Guillemaud, J. Bergé, N. Pasteur, and M. RayMOND. 1996. Coamplification of A and B esterase genes as a single unit in Culex pipiens mosquitoes. Heredity 77:555-561.

Severini, C., R. Romi, M. Marinucci, and M. Raymond. 1993. Mechanisms of insecticide resistance in the field populations of Culex pipiens from Italy. J. Am. Mosq. Contr. Assoc. 9:164168.

Severini, C., R. Romi, M. Marinucci, T. Gulllemaud, and M. RAYMOND. In press. Esterase A5-B5 in organophosphate-resistant Culex pipiens from Italy. Med. Vet. Entomol.

SinĖgre, G., M. Babinot, J.-M. Quermel, ANd B. Gaven. 1994. First field occurrence of Culex pipiens resistance to Bacillus sphaericus in southern France. P. 17 in VIIIth European meeting of society for vector ecology. Barcelona, Spain.

SZYMURA, J., AND N. H. BARTON. 1986. Genetic analysis of a hybrid zone between the fire-bellied toads, Bombina bombina and $B$. variegata, near Cracow in southern Poland. Evolution 40:11411159.

TAylor, M., And R. Feyereisen. 1996. Molecular biology and evolution of resistance to toxicants. Mol. Biol. Evol. 13:719734

Trebst, A. 1996. The molecular basis of plant resistance to photosystem. II. Herbicides. Pp. 44-51 in T. M. Brown, ed. Molecular genetics and ecology of pesticide resistance. American Chemical Society, Washington, DC.

VILLANI, F, AND J. HemingWAY. 1987. The detection and interaction of multiple organophosphorus and carbamate insecticide resistance genes in field populations of Culex pipiens from Italy. Pest. Biochem. Physiol. 27:218-28.

Williamson, M. S., D. Martinez-Torrez, C. A. Hick, N. CasTELLS, AND A. L. DEVONSHIRE. 1996. Analysis of sodium-channel gene sequences in pyrethroid-resistant houseflies: progress toward a molecular diagnostic for knockdown resistant $(k d r)$. Pp. 52-61 in T. M. Brown, ed. Molecular genetics and evolution of pesticide resistance. American Chemical Society, Washington, DC.

Wirth, M., M. Marquine, G. P. Georghiou, and N. Pasteur. 1990. Esterase A2 and B2 in Culex quiquefasciatus (Diptera: Culicidae): role in organophosphate resistance and linkage. J. Econom. Entomol. 27:202-206.

WRIGHT, S. 1968. Evolution and the genetics of populations. Univ. of Chicago Press, Chicago.

Corresponding Editor: J. Werren 